\title{
Diet quality improvement and 30-year population health and economic outcomes: a microsimulation study
}

\author{
Patricia M Herman* (1), PhuongGiang Nguyen and Roland Sturm \\ RAND Corporation, PO Box 2138, 1776 Main Street, Santa Monica, CA 90407-2138, USA
}

Submitted 11 September 2020: Final revision received 8 December 2020: Accepted 5 January 2021: First published online 13 January 2021

\begin{abstract}
Objective: Diets closer aligned with nutritional guidelines could lower the risk of several chronic conditions and improve economic outcomes, such as employment and healthcare costs. However, little is known about the range, order of magnitude and timing of these potential effects.

Design: We used a microsimulation approach to predict US population changes over 30 years in health and economic outcomes that could result from a substantial (but not impossible) improvement in diet quality - an improvement from the third to the fifth quintile of US scores on the Alternate Healthy Eating Index, 2010 version.

Setting: Risk ratios from the literature for diabetes, heart disease and stroke were used to modify the Future Adult Model (FAM) to simulate outcomes from a higherquality diet. Model parameter uncertainty was assessed using bootstrap and sensitivity analysis examined the variation in published risk ratios.

Participants: FAM simulates outcomes for the US adult population aged 25 and older.

Results: Improved diet quality initially leads to very small changes in chronic disease prevalence, but these accumulate over time. If diets improved beginning in 2019 , after 30 years diabetes prevalence could be reduced by 5.9 million cases $(11.5 \%)$, heart disease prevalence by 4.0 million cases $(7.2 \%)$ and stroke prevalence by 1.9 million cases $(10 \cdot 3 \%)$. These reductions in disease prevalence would be accompanied that same year by fewer deaths (88 000) and healthcare cost savings of $\$ 144 \cdot 0$ billion (2019 USD).

Conclusions: This microsimulation study suggests that improvements in diet are likely to improve health and economic population outcomes over time.
\end{abstract}

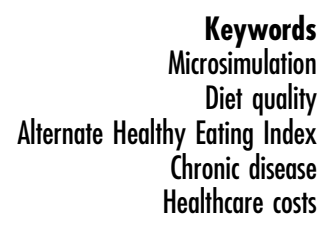

Poor diet quality is a risk factor for multiple chronic conditions, including CVD, type 2 diabetes and some cancers ${ }^{(1)}$. In 2017, the Global Burden of Disease Study attributed 11 million deaths among adults 25 or older worldwide to dietary risk factors ${ }^{(2)}$. Dietary factors independent from overweight/obesity were believed to be responsible for $18 \%$ of all deaths in North America and for $22 \%$ of all deaths (and $49 \%$ of deaths from CVD) in Europe ${ }^{(2,3)}$. In the USA, dietary risks were the primary cause of death and third leading cause of morbidity in $2016^{(4)}$.

Three conceptual approaches have been used to connect dietary factors to health: nutrients, individual foods or eating patterns (complete diets). Nutrients are components of foods that are essential for human health, but new compounds continue to be identified in foods and there can be synergistic interactions between nutrients ${ }^{(5)}$.

Even individual foods (or food groups) are not consumed in isolation but rather in various combinations over time, that is, an 'eating pattern'. Dietary components of an eating pattern have interactive and cumulative relationships. Therefore, eating patterns are more predictive of overall health status and disease risk than individual foods or nutrients ${ }^{(1,6,7)}$. Index-based measures of eating patterns, such as the Healthy Eating Index (HEI) and the Alternate Healthy Eating Index (AHEI), have been developed to summarise diet quality ${ }^{(8,9)}$. Diets of better quality (scoring higher on these indices) are reliably associated with significant reduction in the risk of all-cause mortality, CVD, cancer and type 2 diabetes ${ }^{(8,10-12)}$.

Although health benefits from following dietary guidelines are established, quantifying the economic impacts of realistic dietary improvements has been more elusive, 
especially when compared with the substantial literature on the cost consequences of obesity, where the large number of studies has warranted several systematic reviews ${ }^{(13-15)}$. A 2017 WHO report reviewed the studies published between 2000 and 2016 on economic costs associated with unhealthy diets and low physical activity ${ }^{(16)}$. This report found evidence from multiple studies on the economic costs of inactivity, but only found a single US study that examined the relationship between diet and (healthcare) costs ${ }^{(17)}$. That study only considered fruit/vegetable consumption (rather than multiple food groups or overall diet) and contrasted Medicare claims among older men by high or low fruit/vegetable intake level.

We identified several additional analyses not included in the WHO review. Scrafford et al. examined the impact of diet quality on $\mathrm{CHD}$, stroke, diabetes and cancer using the HEI-2015, and these conditions plus Alzheimer's disease and hip fractures using the Mediterranean diet score $(\mathrm{MED})^{(18)}$. The current study estimated annual (direct and indirect) cost savings of $\$ 16.7$ billion or $\$ 31.5$ billion (2017 USD) assuming a $20 \%$ increase in diet quality as measured by the MED or HEI-2015, respectively. An improvement to achieve $80 \%$ of maximum MED or HEI-2015 scores was estimated to save $\$ 88.2$ billion or $\$ 55.1$ billion annually, respectively. Abdullah et al. ${ }^{(19)}$ made annual estimates of the direct and indirect economic impacts of a Mediterranean-style diet but only included impacts on CHD and stroke. They estimated savings of $\$ 1.0$ billion to $\$ 62.8$ billion (2014 USD), for 'very-pessimistic' through 'ideal' scenarios for diet improvement. Both studies were static macro-level calculations that combined estimates from the literature on prevalence of diet quality and of targeted chronic diseases in the population, impact of diet quality on health outcomes and healthcare costs associated with each health outcome.

The remaining studies used a microsimulation approach focused on CVD, the CVD-PREDICT model. The authors used estimates from the literature on the health impact of moving to an optimal intake of ten food groups to modify the incidence of CVD in the model. Model results were published for the US population as a whole ${ }^{(20)}$, for the US Supplemental Nutrition Assistance Program population ${ }^{(21)}$ and for Medicare and Medicaid participants ${ }^{(22)}$. Annual healthcare cost savings from moving to an optimal intake of the ten food groups for the whole US population were estimated as $\$ 50.4$ billion (2018 USD) ${ }^{(20)}$.

This paper used a different dynamic simulation model, the Future Adult Model (FAM; aka the Future Americans Model). This model has less clinical detail than the CVDPREDICT but addresses the impact of diet on more chronic diseases, provides more information on economic outcomes and predicts these health and economic outcomes over 30 years. We used this model to compare a baseline diet scenario against a hypothetical scenario where diet quality was improved, that is, a 2-quintile increase in the AHEI-2010 ${ }^{(8)}$. This increase corresponds to a median score shift in the AHEI-2010 from 48.6 to 62.7 in women and from 52.2 to 67.6 in men. This hypothetical improvement in diet quality reduced the risk for chronic conditions based on estimates from systematic reviews, and those risk reductions were fed into the FAM to simulate individual life trajectories over 30 years. This approach more realistically reflects the dynamics of population health than static calculations where interventions immediately result in equilibrium outcomes. Improving a health behaviour cannot instantly change the prevalence of chronic disease or retroactively prevent deaths. Rather, it lowers the likely incidence of future events and mortality. The benefits of better diet, whether in terms of health or economic outcomes, will only accrue over time.

\section{Methods}

The current study integrates the impact from the literature on disease incidence from a hypothetical change in diet quality with the FAM microsimulation to determine the impact on health and economic outcomes in the US adult population over 30 years. The RAND Human Subjects Protection Committee has determined that this project does not involve human subjects.

\section{The Future Adult Microsimulation Model}

The FAM is a dynamic microsimulation model that simulates individual life trajectories for a hypothetical cohort of US adults 25 years of age and older. The primary engine of the FAM is a set of transition equations between health states and economic outcomes estimated from the Panel Study of Income Dynamics (PSID). These estimates primarily used PSID data from 2001 through 2015. The transition module ages individuals over time. The simulated transitions are in 2-year steps and at every step a new group of 25/26-year-olds are added through a replenishing module. The replenishing module synthetically generates new members to match observed correlations between variables in the PSID adjusted for predicted trends in population demographics from the census and behavioural changes based on the National Health Interview Survey and the National Health and Nutrition Examination Survey.

In the transition module risk factors, chronic diseases, functional limitations and economic outcomes change probabilistically over time via estimated transition equations based on what was seen in the PSID data over time. Other characteristics of the individual do not change over time (e.g., sex, race/ethnicity or parents' education) or are deterministic (e.g., age, characteristics that are a consequence of age such as Medicare eligibility). At times, the presence of certain chronic diseases affects the incidence models for other chronic diseases. For example, the presence of heart disease, cancer, hypertension and/or diabetes in one period affects the incidence of stroke in the next 
period. Hypertension and/or diabetes in one period affects the incidence of heart disease in the next period, and the presence of diabetes in one period affects the incidence of hypertension in the next period. More details on the FAM, including information on its validation, are found in its Technical Documentation ${ }^{(23)}$.

Medical expenditures depend on individual's chronic conditions, functional limitations and socio-demographics and are based on data from the Medical Expenditures Panel Survey (http://meps.ahrq.gov/mepsweb/) and Medicare Current Beneficiary Survey. We assumed our 'intervention' (assuming everyone moves from average to high-quality diets) changed the probabilities of transitions into chronic disease states for all individuals of the same gender by the same proportion. This simplification was necessary as we have no basis from the literature to assign differential effects of diet quality by socio-demographic characteristics, except for distinguishing men and women.

\section{Model outcomes}

The FAM model produces estimated outcomes for several components of the PSID survey (general health status, activities of daily living, incidence of disease, employment and use of social programmes), plus healthcare costs and quality-adjusted life-years from Medical Expenditures Panel Survey and Medicare Current Beneficiary Survey, for every 2 years over 30 years. The prevalence of diagnosed chronic disease is based on questions of the format 'has a doctor ever told you that you have:' diabetes, heart disease (which includes CHD, angina, congestive heart failure), stroke or cancer (or malignant tumour, excluding skin cancer). The PSID also captures general health status (using five-point scale from $1=$ poor to $5=$ excellent), and whether a person is disabled (difficulty doing any of a list of activities of daily living or instrumental activities of daily living by yourself or living in a nursing home). Economic outcomes include total healthcare costs (whether paid by government, private insurance or patients out-of-pocket) from Medical Expenditures Panel Survey and Medicare Current Beneficiary Survey and from the PSID whether the individual was working for pay and using Social Security and other income support programmes.

\section{Diet quality and its impact on bealth}

Many studies have examined the impact of diet quality on chronic disease incidence and mortality using large epidemiological studies and a range of different measures of diet quality and health outcomes ${ }^{(10,24)}$. The publications reporting relative risks (RR) or hazard ratios for disease incidence, rather than mortality, were the best fit for incorporating into the structure of the FAM. After reviewing studies included in a large systematic review of the impact of diet quality on health ${ }^{(10)}$, we utilised diet quality/disease estimates from a high-quality study (eight out of nine on the Ottawa Quality Assessment Scale ${ }^{(12,25)}$ ) by Chiuve et $a l^{(8)}$, to inform the diet quality/disease risk link in our analysis.

The Chiuve et al. study ${ }^{(8)}$ was based on the analysis of two large datasets (the Nurses' Health Study for women, $n$ 79 495; and the Health Professionals Study for men, $n 41029)$ and used the AHEI-2010 ${ }^{(7)}$. The AHEI-2010 is derived from recent (2010) evidence of foods and nutrients predictive of chronic disease risk. Scores on the AHEI-2010 range from 0 to 110 with intakes on eleven food components each adding 0-10 points to the score (Table 1). The Chiuve et al. study used a consistent methodology to calculate RR for men and women and for the incidence of four chronic diseases tracked in the FAM and known to be affected by diet quality: diabetes, heart disease, stroke and cancer. The RR were estimated from multivariate Cox proportional hazard models adjusted for: age, energy ( $\mathrm{kcal} / \mathrm{d})$, smoking status, BMI, aspirin use, physical activity, vitamin E supplementation, family history of myocardial infarction and colon cancer, personal history of hypertension and hypercholesterolaemia (except for the cancer model), and in women, family history of breast cancer, menopausal status and use of hormone therapy. The multivariate-adjusted RR (with $95 \% \mathrm{CI}$ ) for each quintile of diet quality compared with the first (lowest, reference) quintile are shown in Table 2.

The 'intervention' we analysed was a hypothetical improvement in diet quality from the third quintile to the fifth quintile - a substantial, but not impossible improvement. Key model assumptions were that: (1) the third quintile represented average diet quality for the US population in the base case and (2) with the intervention diet quality improved to the fifth quintile and stayed there for the duration of the model. The RR for that improvement was calculated as the ratio of the RR for those quintiles, shown in the second-to-last column in Table 2.

\section{Analysis}

All FAM outcomes and total population were projected over 30 years assuming the intervention started in 2019. Medical costs were adjusted to 2019 USD using the medical component of the Consumer Price Index (United States Bureau of Labor Statistics). We adjusted for time preferences by discounting costs and quality-adjusted life-years at a constant rate of $3 \%$.

The parameters (transition probabilities) in the FAM were estimated from the PSID. To account for uncertainty in those estimates, we employed a non-parametric bootstrap approach. We resampled individuals from PSID, estimated parameters for this bootstrap sample and then simulated population outcomes. We used 100 bootstrap replications, and from these SD we calculated $95 \% \mathrm{CI}$ (means of the outcomes are assumed to be normally distributed).

We separately considered the sensitivity of our results to uncertainty in our intervention assumptions by estimating outcomes based on RR that were one SE above and below those used in the base case (Table 2).

All results were calculated using the FAM, Version $202^{(23)}$. 
Table 1 Scoring for the Alternate Healthy Eating Index, 2010

\begin{tabular}{|c|c|c|}
\hline Food component & Minimum score $(0=$ worse diet $)$ & Maximum score $(10=$ best diet $)$ \\
\hline Vegetables, servings/d & 0 & $>=5$ \\
\hline Fruit, servings/d & 0 & $>=4$ \\
\hline Whole grain, $g / d$ & 0 & 75 for women; 90 for men \\
\hline $\begin{array}{l}\text { Sugar-sweetened beverages and fruit juice, } \\
\text { servings/d }\end{array}$ & $>=1$ & 0 \\
\hline $\begin{array}{l}\text { Nuts and legumes (lentils, beans and peanuts), } \\
\text { servings/d }\end{array}$ & 0 & $>=1$ \\
\hline Red and processed meat, servings/d & $>=1.5$ & 0 (<1 per month) \\
\hline Trans-fat, $\%$ of energy & $>=4 \%$ & $<=0.5 \%$ \\
\hline $\begin{array}{l}\text { Long-chain }(n-3 \text { or } n-3) \text { fats }(E P A+D H A), m g / d \\
\text { PUFA or fats (PUFA), \% of energy }\end{array}$ & $\begin{array}{c}0 \\
<=2 \%\end{array}$ & $\begin{array}{c}250 \\
>=10 \%\end{array}$ \\
\hline $\mathrm{Na}$ (salt), mg/d & $\begin{array}{c}>=3337 \mathrm{mg} / \mathrm{d} \text { for women; }>=5271 \mathrm{mg} / \mathrm{d} \\
\text { for men }\end{array}$ & $\begin{array}{c}<=1112 \mathrm{mg} / \mathrm{d} \text { for women; }<=1612 \mathrm{mg} / \mathrm{d} \\
\text { for men }\end{array}$ \\
\hline Alcohol, drinks/d & $\begin{array}{l}>=2.5 \text { for women } \\
>=4.5 \text { for men }\end{array}$ & $\begin{array}{l}0.5-1.5 \text { for women } \\
0.5-2 \text { for men }\end{array}$ \\
\hline Total & 0 & 110 \\
\hline
\end{tabular}

Source: Adapted from Table 1 in Chiuve et al. J Nutr 2012; 142: 1009-1018.

\section{Results}

Table 3 shows the results from the FAM for a 2-quintile improvement in diet quality in US adults 10 and 30 years after initiation (2019) and differences compared with the status quo. Reductions in the future prevalence of diabetes, heart disease and stroke would be substantial - but only over time, not immediately, from 5.0 to $7.5 \%$ fewer cases in year 10 and from $7 \cdot 2$ to $11.5 \%$ fewer cases in year 30 . Reductions in the prevalence of all types of cancer were more modest: $1.2 \%$ fewer cases in year 10 and $0.7 \%$ fewer cases in year 30 .

Improved diet quality would also result in fewer people rating their health as fair or poor, and fewer people with either one (morbidity) or two or more (co-morbidity) chronic diseases. Fewer people would have died and the population would have gained almost 230 million additional quality-adjusted life-years in year 30.

Although the reduced mortality means that more people are alive and would use medical care, total medical costs decrease with improved diet quality. Expressed in 2019 USD, medical expenditures would decrease by $\$ 66.9$ billion in year 10 and $\$ 144.0$ billion in year 30 . These amounts represent reductions of 1.5 and $1.7 \%$ of total healthcare expenditures in those years. Figure 1 shows how the reductions in medical expenditures increase over time. Other economic benefits include 710000 more people working for pay, and 17000 fewer Supplemental Social Security Income claims, 199000 fewer people considered disabled and 180000 fewer Disability Insurance claims in year 30. Because people will live longer, our simulations show that an improved diet would mean just over a million additional individuals in the USA receiving Social Security payments that year. Interactive graphic presentation of the health and economic impacts of our assumed diet quality intervention over time is available on this link:https:// www.rand.org/pubs/tools/TL363.html.
Table 4 shows the results of the sensitivity analysis examining the uncertainty in the impact of improved diet quality RR we obtained from the literature. Except for cancer, the reductions in prevalence were maintained even at one SE below the RR estimates.

\section{Discussion}

Improvements in diet quality can have a substantial impact on population health, as well as a variety of economic outcomes. Using microsimulation, the FAM captures the impact of an improvement in diet quality on the number of new cases of chronic disease over the course of 30 years. In general, this model demonstrates how an improved diet can lead to an ongoing accumulation of better health and economic outcomes for the future. However, the dynamics can be complicated for specific conditions. For example, the reduction in prevalence of all cancers is greater at year 10 than at year 30. This is because fewer people are dying of diabetes, heart disease and stroke, and they live long enough to get cancer. There is a similar trend in the prevalence of those considered disabled in year 10, which is less than in year 30 for the same reason, because individuals are projected to live longer. As the incidence of chronic disease is avoided, there are fewer and fewer deaths each year until about year 10. However, from then until year 30 the death rate remains roughly constant as people age and die from other causes.

The most significant impact from improved diet quality on chronic disease incidence occurs in diabetes and heart disease, almost 6 million and 4 million fewer cases, respectively, in year 30 . However, in terms of reducing the proportion of new cases, it is stroke ( $10 \%$ fewer cases) that is second to diabetes (almost $12 \%$ fewer cases). Diet quality does have some impact on cancer incidence with almost 230000 or $1 \%$ fewer cases in year 30, but this impact is substantially smaller than what is seen for other chronic 


\section{Public Health Nutrition}

Table 2 Relative risk of chronic disease by quintile of the Alternate Healthy Eating Index, 2010, for men and women

\begin{tabular}{|c|c|c|c|c|c|c|c|c|c|c|c|c|}
\hline \multirow{2}{*}{$\begin{array}{l}\text { Scores for each } \\
\text { quintile: range and } \\
\text { median }\end{array}$} & \multirow{2}{*}{$\begin{array}{c}\mathrm{Q1} \\
\mathrm{W}<40.336 \cdot 2 \\
\mathrm{M}<42.638 .0\end{array}$} & \multicolumn{2}{|c|}{$\begin{array}{c}\text { Q2 } \\
\text { W 40.3-46.0 } 43 \cdot 4 \\
\text { M 42.6-49.2 } 46 \cdot 1\end{array}$} & \multicolumn{2}{|c|}{$\begin{array}{c}\text { Q3 } \\
\text { W 46.1-51.3 48.6 } \\
\text { M 49.3-55.2 52.2 }\end{array}$} & \multicolumn{2}{|c|}{$\begin{array}{c}\text { Q4 } \\
\text { W 51.4-57.8 } 54.3 \\
\text { M 55.3-62.3 58.4 }\end{array}$} & \multicolumn{2}{|c|}{$\begin{array}{c}\text { Q5 } \\
W>57.862 .7 \\
M>62.367 .6\end{array}$} & \multicolumn{2}{|c|}{$\begin{array}{l}\text { Relative risk for } \\
\text { assumed interven- } \\
\text { tion Q5/Q3 }\end{array}$} & \multirow{2}{*}{$\begin{array}{l}1 \mathrm{SE} \text { above, } 1 \mathrm{SE} \\
\text { below intervention RR } \\
\text { for sensitivity }\end{array}$} \\
\hline & & $\mathrm{RR}$ & $95 \% \mathrm{Cl}$ & $\mathrm{RR}$ & $95 \% \mathrm{Cl}$ & $\mathrm{RR}$ & $95 \% \mathrm{Cl}$ & $\mathrm{RR}$ & $95 \% \mathrm{Cl}$ & $\mathrm{RR}$ & $95 \% \mathrm{Cl}$ & \\
\hline \multicolumn{13}{|l|}{ Heart disease } \\
\hline Women & 1 (ref) & 0.89 & $0.78,1.02$ & 0.74 & $0.64,0.86$ & 0.72 & $0.62,0.84$ & 0.67 & $0.58,0.78$ & 0.91 & $0.72,1.09$ & $0.81,1.00$ \\
\hline Men & 1 (ref) & 1.01 & $0.89,1.14$ & 0.81 & $0.71,0.92$ & 0.78 & $0.68,0.89$ & 0.70 & $0.61,0.80$ & 0.86 & $0.70,1.03$ & $0.78,0.95$ \\
\hline \multicolumn{13}{|l|}{ Stroke } \\
\hline Women & 1 (ref) & 0.92 & $0.79,1.07$ & 0.95 & $0.82,1.11$ & 0.83 & $0.71,0.97$ & 0.83 & $0.71,0.97$ & 0.87 & $0.68,1.06$ & $0.78,0.97$ \\
\hline Men & 1 (ref) & 0.90 & $0.74,1.11$ & 0.86 & $0.70,1.05$ & 0.85 & $0.70,1.04$ & 0.76 & $0.62,0.94$ & 0.88 & $0.63,1.14$ & $0.75,1.01$ \\
\hline \multicolumn{13}{|l|}{ Diabetes } \\
\hline Women & 1 (ref) & 0.88 & $0.81,0.94$ & 0.81 & $0.75,0.87$ & 0.74 & $0.68,0.80$ & 0.65 & $0.59,0.71$ & 0.80 & $0.71,0.90$ & $0.75,0.85$ \\
\hline Men & 1 (ref) & 0.89 & $0.78,1.00$ & 0.85 & $0.75,0.96$ & 0.84 & $0.74,0.95$ & 0.72 & $0.63,0.82$ & 0.85 & $0.69,1.00$ & $0.77,0.93$ \\
\hline \multicolumn{13}{|l|}{ Cancer } \\
\hline Women & 1 (ref) & 0.94 & $0.89,1.00$ & 0.96 & $0.91,1.02$ & 0.90 & $0.85,0.95$ & 0.93 & $0.88,0.99$ & 0.97 & $0.89,1.05$ & $0.93,1.01$ \\
\hline Men & 1 (ref) & 0.97 & $0.89,1.05$ & 0.96 & $0.88,1.04$ & 0.93 & $0.85,1.01$ & 0.94 & $0.87,1.03$ & 0.98 & $0.86,1.10$ & $0.92,1.04$ \\
\hline
\end{tabular}

$\mathrm{Q}$, quintile; W, women; M, men; RR, relative risk.

Source for the estimates by quintile: Adapted from Table 3 in Chiuve et al. J Nutr 2012; 142: 1009-1018. 
Table 3 Results from the Future Adult Model of a 2-quintile improvement in diet quality 10 and 30 years after initiation (2019) compared with the status quo

\begin{tabular}{|c|c|c|c|c|c|c|c|c|}
\hline & \multicolumn{4}{|c|}{ Year 10 (2029) } & \multicolumn{4}{|c|}{ Year 30 (2049) } \\
\hline & Mean & $95 \% \mathrm{Cl}$ & $\begin{array}{l}\text { Difference from } \\
\text { status quo }\end{array}$ & $\%$ & Mean & $95 \% \mathrm{Cl}$ & $\begin{array}{l}\text { Difference from } \\
\text { status quo }\end{array}$ & $\%$ \\
\hline \multicolumn{9}{|l|}{$\begin{array}{l}\text { Prevalence of chronic disease } \\
\text { (millions) }\end{array}$} \\
\hline Diabetes & $35 \cdot 9$ & $34 \cdot 1,37 \cdot 7$ & $-2 \cdot 9$ & -7.5 & $45 \cdot 3$ & $42 \cdot 5,48 \cdot 2$ & $-5 \cdot 9$ & -11.5 \\
\hline Heart disease & $42 \cdot 0$ & $39 \cdot 9,44 \cdot 0$ & $-2 \cdot 2$ & $-5 \cdot 0$ & 51.5 & $48 \cdot 3,54 \cdot 6$ & $-4 \cdot 0$ & $-7 \cdot 2$ \\
\hline Stroke & $12 \cdot 3$ & $10 \cdot 9,13 \cdot 6$ & $-1 \cdot 0$ & $-7 \cdot 4$ & $16 \cdot 9$ & $14 \cdot 5,19 \cdot 2$ & -1.9 & $-10 \cdot 3$ \\
\hline Cancer & $25 \cdot 9$ & $24 \cdot 3,27 \cdot 5$ & -0.3 & $-1 \cdot 2$ & $32 \cdot 1$ & $29 \cdot 7,34 \cdot 6$ & -0.2 & -0.7 \\
\hline \multicolumn{9}{|l|}{$\begin{array}{l}\text { Other measures of health } \\
\text { (millions) }\end{array}$} \\
\hline $\begin{array}{l}\text { Self-report of health (fair or } \\
\text { poor) }\end{array}$ & $25 \cdot 0$ & $24 \cdot 9,25 \cdot 2$ & $0 \cdot 0$ & $0 \cdot 1$ & $21 \cdot 3$ & $21 \cdot 1,21 \cdot 5$ & $0 \cdot 1$ & 0.7 \\
\hline $\begin{array}{l}\text { Quality-adjusted life-years } \\
\text { (QALYs) gained }\end{array}$ & $207 \cdot 4$ & $206 \cdot 4,208 \cdot 4$ & 0.5 & 0.2 & $229 \cdot 4$ & $227 \cdot 6,231 \cdot 2$ & $1 \cdot 7$ & $0 \cdot 8$ \\
\hline \multicolumn{9}{|c|}{ Other conditions - millions of cases/deaths in each year } \\
\hline $\begin{array}{l}\text { Disability (difficulties with } \\
\text { ADL/IADL or nursing home) }\end{array}$ & $54 \cdot 6$ & $52 \cdot 2,56 \cdot 9$ & $-0 \cdot 2$ & -0.5 & $66 \cdot 3$ & $63 \cdot 5,69 \cdot 2$ & -0.2 & -0.3 \\
\hline Morbidity* & $137 \cdot 7$ & $135.9,139.5$ & $-1 \cdot 4$ & $-1 \cdot 0$ & $162 \cdot 3$ & $160 \cdot 2,164 \cdot 3$ & $-1 \cdot 2$ & -0.7 \\
\hline Co-morbidity† & 65.9 & $63 \cdot 9,67 \cdot 9$ & $-2 \cdot 3$ & $-3 \cdot 3$ & $84 \cdot 8$ & $82 \cdot 2,87 \cdot 4$ & $-3 \cdot 8$ & $-4 \cdot 2$ \\
\hline Deaths & $6 \cdot 7$ & $6 \cdot 6,6 \cdot 8$ & $-0 \cdot 1$ & $-1 \cdot 3$ & 8.4 & $8 \cdot 3,8.5$ & $-0 \cdot 1$ & $-1 \cdot 0$ \\
\hline \multicolumn{9}{|c|}{ Economic outcomes - dollar amount or millions in each year } \\
\hline $\begin{array}{l}\text { Total medical spending } \\
\text { (billions, } 2019 \text { USD) }\end{array}$ & $\$ 4424 \cdot 7$ & $4372 \cdot 5,4476 \cdot 9$ & $-\$ 65.9$ & -1.5 & $\$ 8445 \cdot 1$ & $8351 \cdot 8,8538 \cdot 4$ & $-\$ 144 \cdot 0$ & $-1 \cdot 7$ \\
\hline People working for pay & $152 \cdot 9$ & $151 \cdot 1,154 \cdot 6$ & 0.2 & 0.1 & $174 \cdot 2$ & $171 \cdot 9,176 \cdot 5$ & 0.7 & 0.4 \\
\hline Social Security (OASI) claims & $66 \cdot 6$ & $63 \cdot 8,69 \cdot 5$ & $0 \cdot 1$ & 0.2 & $76 \cdot 5$ & $70 \cdot 0,83 \cdot 0$ & $1 \cdot 0$ & $1 \cdot 3$ \\
\hline $\begin{array}{l}\text { Supplemental Social Security } \\
\text { Income claims }\end{array}$ & $2 \cdot 5$ & $2 \cdot 5,2 \cdot 5$ & 0.0 & 0.1 & $1 \cdot 7$ & $1 \cdot 7,1 \cdot 7$ & 0.0 & $1 \cdot 0$ \\
\hline Disability Insurance claims & $7 \cdot 3$ & $4.8,9.9$ & -0.1 & -0.8 & $8 \cdot 2$ & $5 \cdot 8,10 \cdot 6$ & -0.2 & $-2 \cdot 1$ \\
\hline
\end{tabular}

ADL, activities of daily living, that is, daily self-care activities; IADL, instrumental activities of daily living, that is, those activities that allow an individual to live independently in a community.

*Presence of any of these chronic diseases: diabetes, heart disease, stroke, cancer, lung disease or hypertension.

†Presence of two or more of these six chronic diseases: diabetes, heart disease, stroke, cancer, lung disease or hypertension.

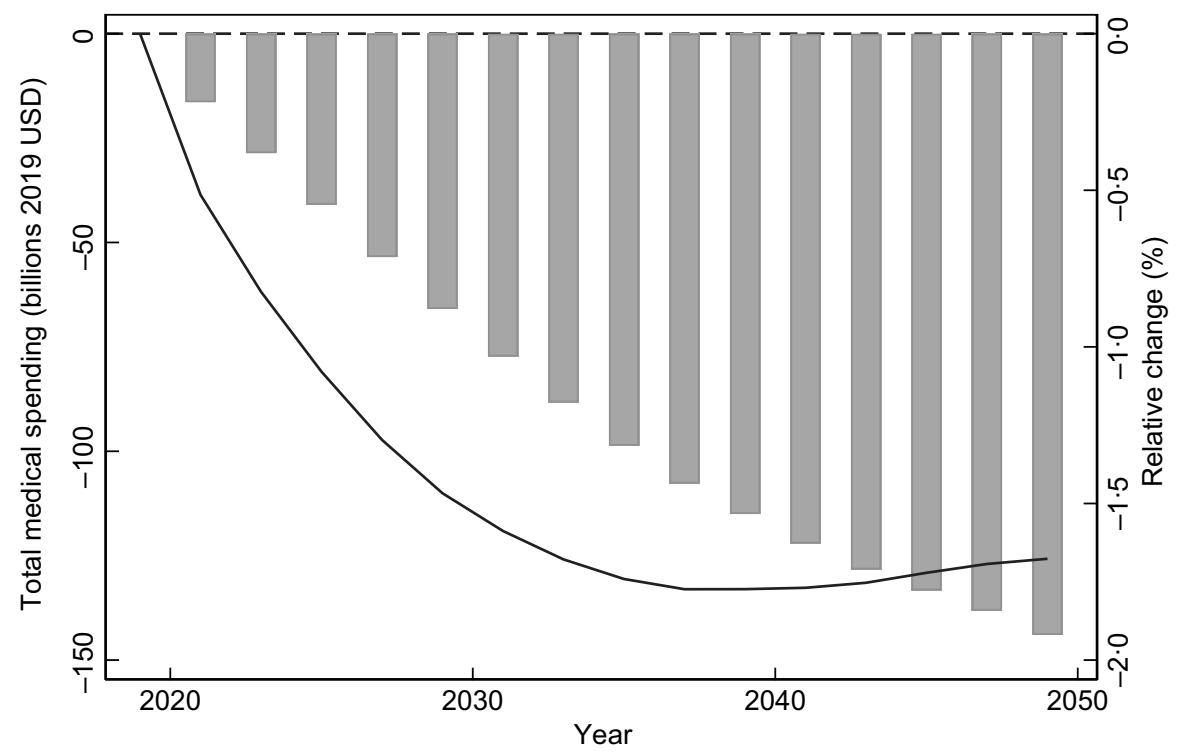

Fig. 1 (colour online) Annual reductions in healthcare expenditures from improved diet quality (2019 USD). $\square$, Absolute change (\$); -, relative change $(\%)$

diseases. This is likely because diet quality mainly effects the incidence of colorectal cancer ${ }^{(26)}$, and despite colorectal cancer being the third most common type of cancer, it only constitutes about $8.3 \%$ of all new cancer cases ${ }^{(27)}$.
We estimated that the diet quality intervention would lower healthcare costs every year across the 30-year study timeline with annual savings in year 10 of $\$ 65.9$ billion and $\$ 144.0$ billion in year 30 (2019 USD). The Scrafford et al. 
Table 4 Sensitivity analysis of the effect of a 2-quintile improvement in diet quality 10 and 30 years after initiation (2019) compared with the status quo

\begin{tabular}{|c|c|c|c|c|c|c|c|c|c|c|c|c|}
\hline & \multicolumn{6}{|c|}{$\begin{array}{c}\text { Year } 10 \text { (2029) } \\
\text { Difference from status quo (\%) }\end{array}$} & \multicolumn{6}{|c|}{$\begin{array}{c}\text { Year } 30 \text { (2049) } \\
\text { Difference from status quo (\%) }\end{array}$} \\
\hline & $\begin{array}{l}\text { Base } \\
\text { case }\end{array}$ & $\%$ & $\begin{array}{l}1 \text { SE above } \\
\text { mean RR }\end{array}$ & $\%$ & $\begin{array}{l}1 \mathrm{SE} \text { below } \\
\text { mean RR }\end{array}$ & $\%$ & $\begin{array}{l}\text { Base } \\
\text { case }\end{array}$ & $\%$ & $\begin{array}{l}1 \text { SE above } \\
\text { mean RR }\end{array}$ & $\%$ & $\begin{array}{l}1 \text { SE below } \\
\text { mean RR }\end{array}$ & $\%$ \\
\hline \multicolumn{13}{|c|}{ Prevalence of chronic disease (millions) } \\
\hline Diabetes & -2.9 & -7.5 & -1.9 & $-5 \cdot 0$ & $-4 \cdot 1$ & -10.5 & $-5 \cdot 9$ & -11.5 & -3.9 & -7.5 & $-8 \cdot 1$ & $-15 \cdot 7$ \\
\hline $\begin{array}{l}\text { Heart } \\
\text { disease }\end{array}$ & $-2 \cdot 2$ & $-5 \cdot 0$ & -0.7 & -1.5 & $-4 \cdot 0$ & $-9 \cdot 1$ & $-4 \cdot 0$ & $-7 \cdot 2$ & $-1 \cdot 0$ & $-1 \cdot 8$ & $-7 \cdot 1$ & $-12 \cdot 8$ \\
\hline Stroke & $-1 \cdot 0$ & $-7 \cdot 4$ & $-0 \cdot 1$ & -0.8 & $-2 \cdot 0$ & -14.5 & -1.9 & $-10 \cdot 3$ & -0.2 & $-1 \cdot 0$ & $-3 \cdot 8$ & -19.5 \\
\hline Cancer & -0.3 & $-1 \cdot 2$ & 0.4 & 1.6 & -0.8 & $-3 \cdot 2$ & -0.2 & -0.7 & 0.9 & $2 \cdot 9$ & -0.9 & $-2 \cdot 8$ \\
\hline
\end{tabular}

$\mathrm{SE}$, standard error of the mean relative risk; RR, relative risk.

study ${ }^{(18)}$ estimated the impact of diet quality on healthcare costs associated with the same chronic diseases as the FAM (CHD, stroke, diabetes and cancer) using the HEI-2015 (very similar to the AHEI-2010) as their measure of diet quality. They estimated annual direct healthcare cost savings from a $20 \%$ increase in the HEI-2015 (moving from an average score of 59.3 on a $0-100$ scale to a score of 71.2 ) of $\$ 23.3$ billion (2017 USD) and direct cost savings of $\$ 40.8$ billion from an increase in the HEI-2015 to $80 \%$ of its maximum value (a score of 80). For comparison, our 'intervention' moved diet quality as measured by the AHEI-2010 (range 0-110) from a median of 48.6 for women to 62.7 (29\% increase) and from 52.2 for men to $67.6(30 \%$ increase). An increase to $80 \%$ of the maximum AHEI-2010 score would be an increase to $88(0.8 \times 110)$. Therefore, if we had followed their methodology of applying diet quality RR estimates to current prevalence, our healthcare cost savings estimates, which were based on diet quality score increases of 29 and $30 \%$, should land somewhere between the Scrafford et al. 20 and $80 \%$ estimates. Instead, our year 4 and 6 estimates generally match theirs (after adjusting dollars to similar years using the medical care CPI) possibly indicating a more realistic timing for these outcomes.

The CVD-PREDICT microsimulation ${ }^{(20)}$ assumed optimal intake of different food groups and estimated healthcare cost savings for the US population as a whole of $\$ 50.4$ billion (2018 USD). This model used several risk factors and their change over time to predict CVD and has been validated in terms of CVD mortality ${ }^{(28)}$. The authors adjusted their model using RR estimates from the literature as to the impact of optimal intakes of each of ten food groups on mortality ${ }^{(29)}$. Then they added estimates from various sources of the healthcare costs associated with CVD disease states ${ }^{(20)}$. Model estimates at 5 years were used for their annual healthcare cost savings estimate for the USA as a whole, and their number ( $\$ 50.4$ billion) is higher than what FAM predicted in year 5 (about $\$ 34$ billion). There could be several reasons why the two models would produce different estimates. However, one likely reason is that the FAM analysis moved individuals from mid- to high-quality diets defined by what was has been seen regarding actual diet quality in large samples. In contrast, the Jardim et al. study moved individuals to optimal levels of all food groups, which may not be as attainable.

All simulation studies are inherently speculative and depend on a number of assumptions and inputs that influence results. An advantage of our approach is that we use an internally consistent and well-established model built on panel data from a nationally representative sample that included socio-demographics, health states (including chronic disease) and several personal and household economic indicators. Population-based healthcare costs by disease state and socio-demographics are also part of the FAM, and healthcare cost and other outcomes were predicted over 30 years. One main limitation of our study comes from our need to incorporate estimates from outside the model on the linkage between diet quality and the incidence of chronic disease. We were able to obtain these estimates from one high-quality study that used large sample sizes and consistent methodology to estimate RR for both men and women and across four chronic diseases. However, in using these estimates we had to accept any flaws in the methods including in the diet quality index used. Also, even though the authors used multivariate models that controlled for other chronic diseases, these epidemiology-based estimates were not designed to adjust incidence across a simulation model's causal web of risk factors leading to later outcomes. For example, because the incidence of diabetes affects the incidence of heart disease in the model, it is possible that adjusting both the incidence of diabetes and heart disease for higher diet quality overstates its impact, but the true net effect is unknown.

The most important assumptions, however, were that we modelled a hypothetical improvement in diet quality that moves all adults up by two quintiles on the AHEI2010, that is, going from the third quintile (median scores of 48.6 for women and 52.2 for men) to the fifth quintile (median scores of 62.7 for women and 67.6 for men) of diet quality and we assume this improvement to be maintained for 30 years. Thus, our results should be considered an estimate of the health and economic cost of poor diet quality. We do not address the intervention that could accomplish 
this improvement in diet quality nor its costs. This average intervention runs somewhat counter to the idea of microsimulation and an improved approach in the future would take into account differences in base case diet quality across the population. A shift from the bottom (first quintile) to the middle (third) quintile of diet quality, for example, could have slightly different implications than from the middle to the top (fifth quintile), and average diet quality is known to vary by socio-demographic status ${ }^{(30)}$.

\section{Summary and conclusions}

There are few studies that indicate the health and economic impacts of improved diet quality. The 2019 report by the Global Burden of Disease Collaborators continues to be based on food groups and individual diet components, even though they acknowledge that summing health outcome estimates across individual components, which tend to be correlated, is likely to exaggerate total effects ${ }^{(2)}$. The Global Burden of Disease acknowledges that "use of dietary pattern as the main exposure could potentially address this problem', but has not yet made this switch ${ }^{(31)}$. Diet quality indexes such as the HEI and the AHEI have substantially improved the measurement and understanding of dietary patterns beyond the focus on single foods or individual nutrients ${ }^{(6)}$. Over the last decade, obesity has dominated news headlines, but diet quality has independent and potentially larger health effects ${ }^{(32)}$. This paper used a microsimulation approach to assess the potential health and economic effects of improving diet quality over time. We found substantial reductions in the prevalence of diabetes, heart disease and stroke that increase over time as well as related reductions in associated healthcare costs.

\section{Acknowledgements}

Acknowledgements: We are grateful to Bryan Tysinger for maintaining the microsimulation software, Adrian Salas for executing the cloud computing runs and Pedro Nascimento de Lima for creating a visualisation programme to display results. Financial support: Funding for the current study was provided through a grant from Pharmavite LLC, a dietary supplements company. Pharmavite had no role in the design, analysis or writing of this article. The maintenance of the Future Adult Model at RAND is supported by NIH grant R01HD087257. Conflict of interest: None. Authorship: R.S. and P.M.H. designed the study and collaborated on the first draft. P.N. performed the bulk of the analysis under the supervision of R.S. and built the results tables. All authors read, edited and approved the final draft. Ethics of buman subject participation: RAND's Human Subjects Protection Committee ruled the current study as not qualifying as human subjects research.

\section{References}

1. U.S. Department of Health and Human Services and U.S. Department of Agriculture (2015) 2015-2020 Dietary Guidelines for Americans, 8th ed. Washington, DC: U.S. Department of Health and Human Services and U.S. Department of Agriculture.

2. Global Burden of Disease Diet Collaborators (2019) Health effects of dietary risks in 195 countries, 1990-2017: a systematic analysis for the Global Burden of Disease Study 2017. Lancet 393, 1958-1972.

3. Meier T, Grafe K, Senn F et al. (2019) Cardiovascular mortality attributable to dietary risk factors in 51 countries in the WHO European Region from 1990 to 2016: a systematic analysis of the Global Burden of Disease Study. Eur $J$ Epidemiol 34, 37-55.

4. Mokdad AH, Ballestros K, Echko M et al. (2018) The state of US health, 1990-2016: burden of diseases, injuries, and risk factors among US states. JAMA 319, 1444-1472.

5. Tapsell LC, Neale EP, Satija A et al. (2016) Foods, nutrients, and dietary patterns: interconnections and implications for dietary guidelines. Adv Nutr 7, 445-454.

6. Reedy J \& Subar AF (2018) 90th anniversary commentary: diet quality indexes in nutritional epidemiology inform dietary guidance and public health. J Nutr 148, 1695-1697.

7. Burggraf C, Teuber R, Brosig S et al. (2018) Review of a priori dietary quality indices in relation to their construction criteria. Nutr Rev 76, 747-764.

8. Chiuve SE, Fung TT, Rimm EB et al. (2012) Alternative dietary indices both strongly predict risk of chronic disease. J Nutr 142, 1009-1018.

9. Guenther PM, Kirkpatrick SI, Reedy J et al. (2014) The Healthy Eating Index-2010 is a valid and reliable measure of diet quality according to the 2010 Dietary Guidelines for Americans. J Nutr 144, 399-407.

10. Schwingshackl L, Bogensberger B \& Hoffmann G (2018) Diet quality as assessed by the healthy eating index, alternate healthy eating index, dietary approaches to stop hypertension score, and health outcomes: an updated systematic review and meta-analysis of cohort studies. J Acad Nutr Diet 118, 74-100 e111.

11. Onvani S, Haghighatdoost F, Surkan PJ et al. (2017) Adherence to the healthy eating index and alternative healthy eating index dietary patterns and mortality from all causes, cardiovascular disease and cancer: a meta-analysis of observational studies. J Hum Nutr Diet 30, 216-226.

12. Schwingshackl L \& Hoffmann G (2015) Diet quality as assessed by the healthy eating index, the alternate healthy eating index, the dietary approaches to stop hypertension score, and health outcomes: a systematic review and metaanalysis of cohort studies. J Acad Nutr Diet 115, 780-800. e785.

13. Tremmel M, Gerdtham UG, Nilsson PM et al. (2017) Economic burden of obesity: a systematic literature review. Int J Environ Res Public Health 14, 435.

14. Tsai AG, Williamson DF \& Glick HA (2011) Direct medical cost of overweight and obesity in the USA: a quantitative systematic review. Obes Rev: Offl J Int Assoc Study Obes 12, 50-61.

15. Kim DD \& Basu A (2016) Estimating the medical care costs of obesity in the United States: systematic review, metaanalysis, and empirical analysis. Value Health 19, 602-613.

16. Candari CJ, Cylus J \& Nolte E (2017) Assessing the Economic Costs of Unhealthy Diets and Low Physical Activity: An Evidence Review and Proposed Framework. Health Policy Series no. 47. Copenhagen: WHO Regional Office for Europe.

17. Daviglus ML, Liu K, Pirzada A et al. (2005) Relationship of fruit and vegetable consumption in middle-aged men to medicare expenditures in older age: the Chicago Western Electric Study. J Am Diet Assoc 105, 1735-1744. 
18. Scrafford CG, Bi X, Multani JK et al. (2019) Health economic evaluation modeling shows potential health care cost savings with increased conformance with healthy dietary patterns among adults in the United States. J Acad Nutr Diet 119, 599-616.

19. Abdullah MM, Jones JP \& Jones PJ (2015) Economic benefits of the Mediterranean-style diet consumption in Canada and the United States. Food Nutr Res 59, 27541.

20. Jardim TV, Mozaffarian D, Abrahams-Gessel S et al. (2019) Cardiometabolic disease costs associated with suboptimal diet in the United States: a cost analysis based on a microsimulation model. PLoS Med 16, e1002981.

21. Mozaffarian D, Liu J, Sy S et al. (2018) Cost-effectiveness of financial incentives and disincentives for improving food purchases and health through the US Supplemental Nutrition Assistance Program (SNAP): a microsimulation study. PLoS Med 15, e1002661.

22. Lee Y, Mozaffarian D, Sy S et al. (2019) Cost-effectiveness of financial incentives for improving diet and health through Medicare and Medicaid: a microsimulation study. PLOS Med 16, e1002761.

23. Roybal Center for Health Policy Simulation (2016) The Future Americans Model. https://roybalhealthpolicy.usc.edu/fam/ (accessed June 2020)

24. Onvani S, Haghighatdoost F, Surkan P et al. (2017) Adherence to the healthy eating index and alternative healthy eating index dietary patterns and mortality from all causes, cardiovascular disease and cancer: a meta-analysis of observational studies. J Hum Nutr Diet 30, 216-226.
25. Stang A (2010) Critical evaluation of the Newcastle-Ottawa scale for the assessment of the quality of nonrandomized studies in meta-analyses. Eur J Epidemiol 25, 603-605.

26. Grosso G, Bella F, Godos J et al. (2017) Possible role of diet in cancer: systematic review and multiple meta-analyses of dietary patterns, lifestyle factors, and cancer risk. Nutr Rev 75, 405-419.

27. American Cancer Society (2019) Cancer Facts \& Figures 2019. Atlanta: American Cancer Society.

28. Pandya A, Sy S, Cho S et al. (2017) Validation of a cardiovascular disease policy microsimulation model using both survival and receiver operating characteristic curves. Med Decis Making 37, 802-814.

29. Micha R, Peñalvo JL, Cudhea $\mathrm{F}$ et al. (2017) Association between dietary factors and mortality from heart disease, stroke, and type 2 diabetes in the United States. JAMA 317, 912-924.

30. Hiza HA, Casavale KO, Guenther PM et al. (2013) Diet quality of Americans differs by age, sex, race/ethnicity, income, and education level. I Acad Nutr Diet 113, 297-306.

31. Global Burden of Disease Risk Factors Collaborators (2016) Global, regional, and national comparative risk assessment of 79 behavioural, environmental and occupational, and metabolic risks or clusters of risks, 1990-2015: a systematic analysis for the Global Burden of Disease Study 2015. Lancet 388, 1659-1724.

32. Echouffo-Tcheugui JB \& Ahima RS (2019) Does diet quality or nutrient quantity contribute more to health? J Clin Investig 129, 3969-3970. 